\title{
Review of Governance in Sport: Analysis and Application
}

Edited By Bonnie Tiell and Kerri Cebula. Published in 2021 by Human Kinetics.

Reviewed by Mathew Dowling, Anglia Ruskin University, United Kingdom

There are few topics that have become more of a central interest and concern to sport management scholars and practitioners in recent years than sport governance. With an often bewildering array of textbooks claiming interest and focus on governance, this textbook puts the concept at its core. Tiell and Cebula's contribution offers a valuable insight into this burgeoning research domain. The central premise of the book is that the capacity to govern stems from the power and authority of a sport organization conceptualizing governance, first and foremost, as a legal issue-a much welcomed and needed perspective. For Tiell and Cebula, governance can be understood as the regulatory, legal, and ethical framework by which sport organizations operate. In adopting an applied and analytical approach, Tiell and Cebula overlay a governance perspective on top of the organizational landscape of sport to explore further the processes and implications of governance across all levels (local, state, national, regional, and international). In doing so, the authors provide a comprehensive and accessible introductory text for those new to the topic by exploring how governance occurs and can be recognized within the sport industry, generally and sport organizations, specifically. The textbook is divided into three distinct parts. Part 1: Foundations of governance and authority (Chapters 1-3), outlines the legal, ethical, and regulatory framework in which sport organizations operate. The essence of the argument put forward is that a sport organization's authority, that is, the power to give orders, make decisions, and enforce compliance, stems from its legal status. The importance of an organization's legal status as a source for its authority and power is a consistent theme that runs throughout the book. Part 2: Framework for sport governance (Chapters 4-6) outlines the governing processes at a local, state, regional, national, and international level and distinguishes between the different types of sport organizations that are responsible for overseeing and delivering sport. Of particular note within this section is the breadth of organizations discussed across the not-for-profit, private, and public sectors of sport. Part 3: Governance and authority in sport industry sectors (Chapters 7-14) then delves deeper to explore the governance structures and authority of sport organizations through various subsectors or industries within sport. In this section, the book forays and provides insight into some of the more contemporary and emerging sectors of sport including sporting goods and Esports. The latter is of particular interest, as governing arrangements have yet to be fully established despite the sector witnessing huge growth in recent years. The strength of the textbook is its breadth of coverage, which is both wide-ranging and informative. Tiell and Cebula's contribution lies within its accessibility, applicability, and consistent ability to critically analyze contemporary events and features of sport and how they have been managed or mismanaged through power and authority. In this manner, the book perhaps can be more accurately described as governance with a small " $\mathrm{g}$," in that it attempts to provide a survey of the contemporary sporting landscape in order to make 
sense of the complexities of the governing arrangements within sport. There are few textbooks that are able to achieve this ambitious and laudable goal but Tiell and Cebula's is one of them. This book will be of particular interest to the United States undergraduate readership, although it does have some international flavor and relevance, both within the chapters themselves and through the specific examples used throughout. Consistent with its applied perspective, each chapter begins with a leadoff providing a short excerpt to engage the reader and highlight the importance of the topic area. The use of case studies is also a notable feature of the book, which is of particular benefit and interest for students to engage in topics in a more applied and in-depth manner. Most apparently, the governance in action case studies contained within each chapter provide useful insight for students and a valuable teaching resource for academic staff to examine contemporary issues that can be explained through governance. These, along with the more in-depth web-based case studies, could easily be incorporated into classes to further reinforce and provide an enhanced learning opportunity for students. Tiell and Cebula's Governance in Sport: Analysis and Application textbook will provide a valuable resource for undergraduate sport management or related degree programs, providing contemporary and engaging examples for any classroom. In the book's introduction, the authors boldly claim, "that many textbooks fail to address governance in a way that is interesting and thought provoking" ( $p$. ix). It is clear that this textbook does come close to achieving this-albeit implied-promise, making this textbook of particular interest to introduction to sport management or policy classes and an important and much needed addition to reading lists. 